Document downloaded from:

http://hdl.handle.net/10251/51595

This paper must be cited as:

Cesar Leonardo Trujillo Rodríguez; Velasco De La Fuente, D.; Gabriel Garcerá; Figueres Amorós, E.; Javier Guacaneme (2012). Reconfigurable control scheme for a PV microinverter working in both grid connected and island modes. IEEE Transactions on Industrial Electronics. 59:101-111. doi:10.1109/TIE.2011.2177615.

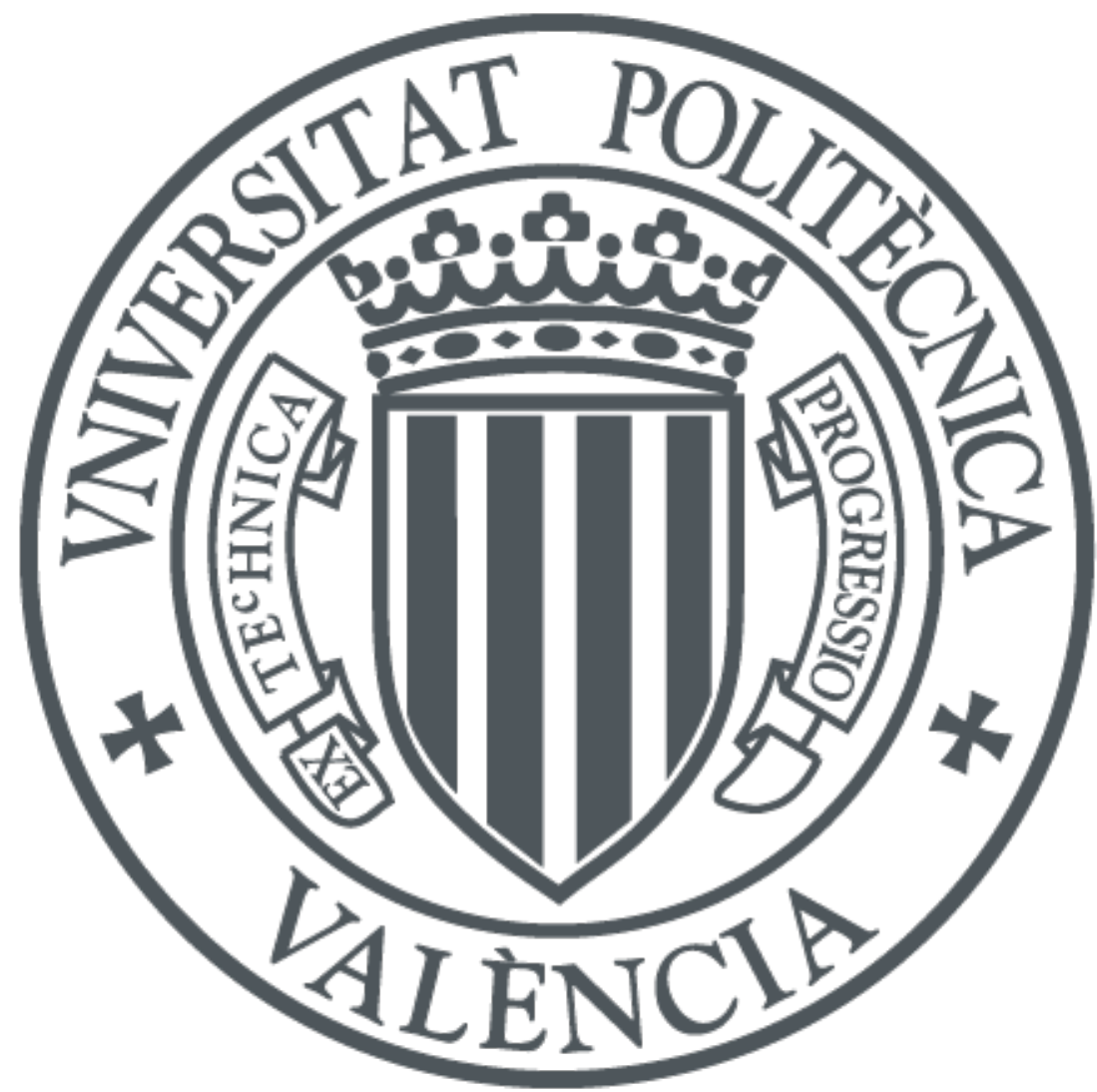

The final publication is available at

http://ieeexplore.ieee.org/xpl/articleDetails.jsp?arnumber=6092481

Copyright Institute of Electrical and Electronics Engineers (IEEE)

Additional Information 


\section{Reconfigurable control scheme for a PV microinverter working in both grid connected and island modes.}

\begin{abstract}
In this paper a photovoltaic microinverter capable of operating in both island mode and grid connected mode by means of a reconfigurable control scheme is proposed. The main advantage of control reconfiguration is that in grid connected mode the microinverter works as a current source in phase with the grid voltage, injecting power to the grid. This is the operation mode of most commercial grid connected PV microinverters. The idea is to provide those microinverters with the additional functionality of working in island mode without changing their control algorithms for grid connected mode, which were developed and refined over time. It is proposed that in island mode the microinverter control is reconfigured to work as a voltage source using droop schemes. These schemes consist in implementing $P / Q$ strategies in the inverters, in order to properly share the power delivered to the loads. The aim of the paper is to show that the proposed control reconfiguration is possible without dangerous transients for the microinverter or the loads. Simulation and experimental results on an $180 \mathrm{~W}$ photovoltaic microinverter are provided to show the feasibility of the proposed control strategy.
\end{abstract}

\section{INTRODUCTION}

In the last years one of the priorities worldwide is developing alternative sources to produce electric energy, especially from renewable sources, which produce low environmental contamination levels. Those renewable energy sources play an important role in the long-term, and they will give rise to substantial changes in the technologic, environmental and organizational profile of the global energy system [1].

Besides, the possibility to produce energy close to the consumption points along with energy delivery problems in isolated and rural areas turn distributed generation (DG) [2] into an interesting and promising technological option.

Accordingly to the expressed above, it is feasible to implement interfaces able to get connected to the grid in order to transfer the energy coming from renewable sources (grid connected mode), as well as to feed local loads when there is a lack of distribution grid (island mode). Those interfaces are known as microgrids [3].

A microgrid is able to flexibly import and export energy from and to the grid. It controls the flow of active and reactive power [4]. The inverters working in a microgrid must be able to work in grid connected mode, injecting power to the distribution grid, as well as in island mode, delivering a proper AC voltage quality to local loads [5].

Most commercial grid connected PV microinverters operate as a current source in phase with the grid voltage, injecting power to the grid [6]. The control algorithms for these microinverters have been developed and refined over time, being highly efficient for grid connected operation. Therefore, many microinverter manufacturing companies may be prone to keep their reliable grid connection control algorithms while incorporating new functions.

The main contribution of this paper is to provide those microinverters with the additional functionality of working in island mode without changing their control algorithms for grid connected mode.

There are several studies about the proper operation of inverters working in both grid connected and island modes. A possible solution is based on droop schemes. These schemes consist in implementing $\mathrm{P} / \mathrm{Q}$ strategies in the inverters, in order to properly share the power delivered to the loads and avoid critical communication lines between inverter modules. In [4] and [7] the inverters are controlled by droop schemes in both operation modes. These inverters are controlled as voltage sources even if they are connected to the grid, so that experienced control algorithms that inject the inverter output current in phase with the grid voltage (current source algorithms) developed for commercial inverters in grid connection mode are discarded.

In [8] it is described that under normal operation the inverter works in a constant current operation mode in order to provide a preset power to the grid. When the islanding situation happens, the inverter must detect it and switch to voltage mode operation. In this mode the islanded inverter will provide a constant voltage to the local load. Additionally, [8] proposes an intelligent load-shedding algorithm for intentional islanding and a synchronization algorithm for grid reconnection. However, the paper does not mention how to parallelize inverters. Furthermore, the reference imposed to the voltage controller has a fixed value.

In [9] it is presented a practical single-phase inverter-based microgrid system that ensures smooth mode transfer between island and grid modes, while maintaining accurate current sharing and high-quality output waveforms. The complete system is implemented using robust CAN communications, including an upper level controller that assigns each inverter to run in voltage or current loop control, a current sharing control and a mode transfer algorithm. However, this system requires a communications bus to operate properly, which means an increased cost.

In other studies like [10] and [11] reconfigurable control schemes are proposed, based on a very simple and effective type of control. This control is the multiloop linear PI control system. This method uses linear inner and outer PI control loops to regulate the system state variables. However, in these 
papers it is not clearly explained how inverters are parallelized sharing the load power.

Given the above, this paper aims to show a reconfigurable control scheme based on multiloop control in both operation modes. Droop schemes are used in the island mode. The idea is to use "current source" control algorithms implemented in commercial microinverters for the grid connected mode, in which case an inner loop provides control of the AC grid injected current, whereas an outer loop regulates the DC voltage at the input of the inverter. In island mode, the inner current loop doesn't change, but the aim of the outer loop is to regulate the inverter output voltage, i.e. a "voltage source algorithm". The voltage controller follows the reference imposed by droop schemes. These schemes are well suited for parallel inverter operation without communication lines among the inverters sharing the load power.

Besides, this paper presents the operation of the microinverter in island mode, without the need of additional energy storage systems, such as batteries and supercapacitors. The microinverter delivers the energy demanded by the load if enough energy is available from the PV panel.

Additionally, in the paper it is shown that the proposed control reconfiguration is possible without dangerous transients for the microinverter or the loads.

This paper is organized as follows. The second section presents the characteristics of a photovoltaic (PV) microinverter working in grid connected mode. The third section shows the method selected for island detection, which determines whether the microinverter is connected to the distribution grid or not. The fourth section presents the characteristics of the microinverter for island mode operation. The fifth section shows the transition between operation modes. Simulation results are provided in the sixth section to illustrate the feasibility of the proposed controllers. The seventh section shows the experimental results. Finally, conclusions are provided.

\section{PV MICROINVERTER SYSTEM DESCRIPTION IN GRID CONNECTED MODE}

Fig. 1 shows the scheme of the PV microinverter that has been implemented. The control configuration corresponds to grid connection mode. The microinverter is fed by a DC programmable source in which the I-V curve of a PV panel has been programmed. The panel voltage is in the range 26$36.7 \mathrm{~V}$ at the maximum power point (MPP), so that a DC-DC stage is needed to raise the voltage supplied by the panel to suitable levels $\left(V_{D C}=380 \mathrm{~V}\right)$ for grid connection of the power processing system. A push-pull DC-DC converter has been chosen for this purpose. For DC-AC conversion a currentcontrolled H-bridge inverter with bipolar PWM [12] with an output LCL filter [13] has been chosen. Note that the use of a push-pull topology provides galvanic isolation without the need of bulky and heavy low frequency transformers.

As it can be observed from Fig. 1, the control of the Pushpull converter starts from a maximum power point tracker (MPPT), implemented by a $\mathrm{P} \& \mathrm{O}$ (perturb and observe) algorithm [14]. The output of the MPPT, $V_{g_{-} r e f}$, is the reference for the PV panel voltage, $V_{g}$. The error between both signals is amplified by a PI voltage controller whose output is the control voltage, $V_{c}$, of the peak current modecontrol loop (PCC) [15]. This control voltage limits the peak value of the current through the primary of the push-pull transformer, avoiding its saturation. The PCC control of the DC-DC converter transformer primary current combined with the control of its input voltage (the PV panel voltage) was proposed in [16] in the context of double-stage PV inverters.

In the PCC PWM modulator an external stabilization ramp, of slope $S_{e}$, is added to the sensed current through the transformer primary (of slope $S_{n}$ ). Fig. 2 shows the control structure of the PCC loop applied to the push-pull converter.

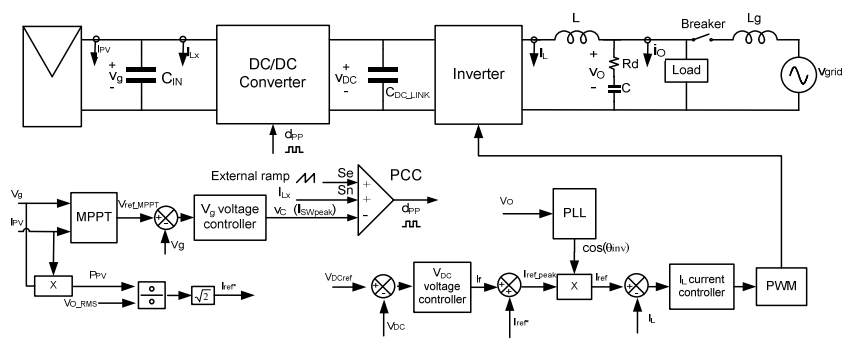

Fig.1. Block diagram of the PV microinverter. The control configuration corresponds to grid connection mode.

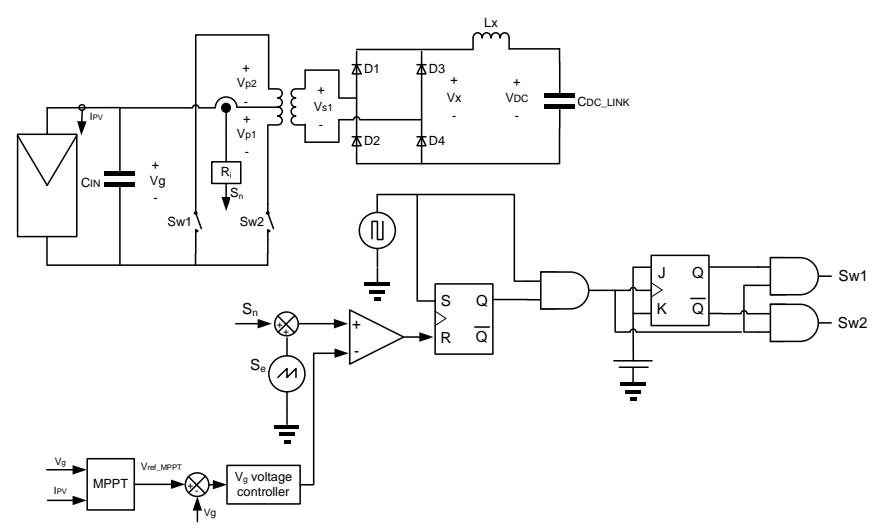

Fig.2. PCC scheme of the push-pull converter for grid connection mode operation.

The PWM inverter has an inner current controller based on a harmonic compensator [17] in order to comply with the IEEE 929-2000 standard [18], in terms of the THD of the current injected to the grid. The amplitude, $I_{\text {ref peak }}$, is the sum the power-feedforward term, used to achieve a fast response of the inverter control to changes in the power generated by the panels [19], and the output of the PI controller of the inverter DC_link voltage, $I_{f}$. This amplitude is multiplied by $\cos \left(\theta_{I N V}\right)$ for synchronization with the fundamental component of the grid voltage. A synchronous rotating reference frame phase locked loop (dqPLL) [20] is used for grid synchronization. Fig. 3 shows the dqPLL block diagram. 


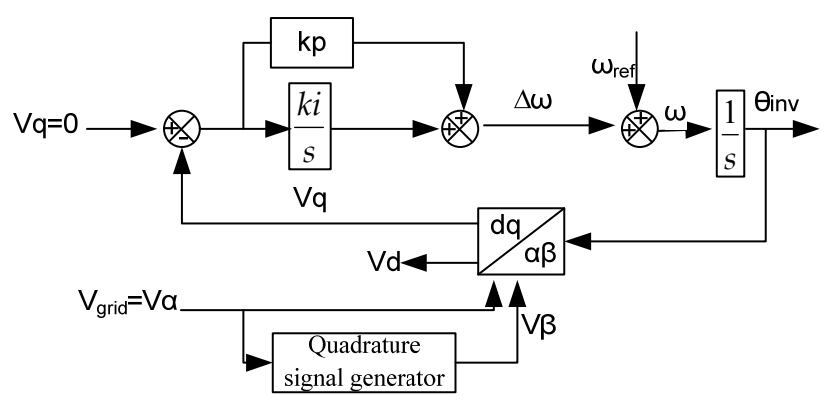

Fig.3. Block diagram of the dqPLL.

Table I shows the electrical parameters of the PV microinverter under study.

TABLE I

ELECTRICAL PARAMETERS OF THE PV MICROINVERTER UNDER STUDY

\begin{tabular}{lc}
\hline \multicolumn{1}{c}{ Parameter } & Values \\
\hline Panel voltage variation $\left(V_{g}\right)$ & {$[24 \mathrm{~V}-36.7 \mathrm{~V}]$} \\
Injected power by panel $\left(P_{p v} M P P\right.$ & $180 \mathrm{~W}$ \\
DC_link voltage $\left(V_{D C}\right)$ & $380 \mathrm{~V}$ \\
Inverter output voltage $\left(V_{O}{ }_{R M S}\right)$ & $230 V_{R M S}$ \\
Inverter output frequency $\left(f_{g}\right)$ & $50 \mathrm{~Hz}$ \\
Push-pull inductance $\left(L_{X}\right)$ & $11 \mathrm{mH}$ \\
Push-pull input capacitance $\left(C_{I N}\right)$ & $470 \mu \mathrm{F}$ \\
Push-pull transformer turns ratio $(N)$ & 20 \\
Push-pull switching frequency $\left(f_{s}\right)$ & $20 \mathrm{kHz}$ \\
DC_link capacitance $\left(C_{D C} L I N K\right)$ & $1 \mathrm{mF}$ \\
Inverter inductance $(L)$ & $19.1 \mathrm{mH}$ \\
Inverter output capacitance $(C)$ & $600 \mathrm{nF}$ \\
Damping resistance $\left(R_{d}\right)$ & $50 \Omega$ \\
Inverter switching frequency $\left(f_{s i}\right)$ & $20 \mathrm{kHz}$ \\
\hline
\end{tabular}

Table II shows the expression of the chosen controllers for both, the inner current loops and the outer voltage loops, along with the corresponding crossover frequencies and phase margins both for the push-pull and for the H-bridge inverter in grid connection operation mode. In table II the term $F_{M}$ is the PWM modulator gain, which depends on $S_{e}$ and $S_{n}$. This value should be adjusted properly in order to guarantee the stability of the current loop [16]. Details about the adjustment of the inverter controllers in grid connected mode can be found in [21].
TABLE II

EXPRESSIONS OF THE CHOSEN CONTROLLERS, CROSSOVER FREQUENCIES AND PHASE MARGINS. GRID CONNECTED MODE.

\begin{tabular}{lccc}
\hline \multicolumn{1}{c}{ Push-pull } & & \\
\hline Controller & Expression in the continuous time & C. freq. & $\begin{array}{c}\text { P. } \\
\text { mar. }\end{array}$ \\
\hline $\begin{array}{l}\text { PWM } \\
\text { modulator } \\
\text { gain. } \\
\mathrm{R}_{\mathrm{i} .} \\
\mathrm{S}_{\mathrm{e} .}\end{array}$ & $F_{M}=\frac{L_{X} \cdot f_{S} \cdot N^{2}}{(1-2 \cdot D) \cdot V_{g} \cdot R_{i}+L_{X} \cdot S_{e} \cdot N^{2}}$ & $2.63 \mathrm{kHz}$ & $66.4^{\circ}$ \\
\hline $\begin{array}{l}\text { Input } \\
\text { voltage } \\
\text { controller }\end{array}$ & $0.015 \Omega$ & & \\
\hline & $-1 \cdot\left(k_{p}+\frac{k_{i}}{s}\right)=-1 \cdot\left(1.5+\frac{300}{s}\right)$ & $98.4 \mathrm{~Hz}$ & $89.6^{\circ}$ \\
\hline $\begin{array}{l}\text { Current } \\
\text { controller }\end{array}$ & $k_{p}+\frac{k_{h} \cdot B_{h} \cdot s}{s^{2}+B_{h} \cdot s+\left(\omega_{h}^{2}\right)}=1.04+\frac{100 \cdot(2 \pi) \cdot s}{s^{2}+2 \pi \cdot s+(100 \pi)^{2}}$ & $1.28 \mathrm{kHz}$ & $58.6^{\circ}$ \\
\hline $\begin{array}{l}\text { DC_link } \\
\text { voltage } \\
\text { controller }\end{array}$ & $-1 \cdot\left(k_{p}+\frac{k_{i}}{s}\right)=-1 \cdot\left(2.5+\frac{0.04}{s}\right)$ & $10 \mathrm{~Hz}$ & $87^{\circ}$ \\
\hline
\end{tabular}

\section{ISLANDING DETECTION METHODS}

The condition of "islanding" in a distributed power generation system is an electrical phenomenon which occurs when the energy supplied by the power grid is interrupted and the distributed generators (DGs) continue energizing some or the entire load. Thus, the power grid stops controlling this isolated part of the distribution system, which contains both loads and generation, so that security, restoration of service and reliability of the equipment may be compromised [22] [23].

The main idea to detect an islanding situation is to supervise the DGs output parameters and/or other system parameters in order to determine if changes indicating an islanding condition have occurred. Islanding detection techniques can be divided into remote and local ones, whereas the latter techniques are divided into passive and active ones, as shown in Fig. 4 [24].

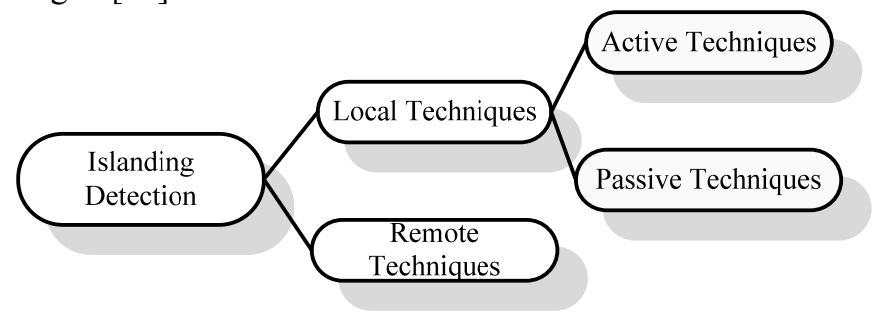

Fig. 4. Anti-islanding techniques classification.

Before defining the different methods of islanding detection, it is important to highlight two key features in order to understand the islanding phenomenon. The first one is associated with the so-called "Non-detection zone" (NDZ). NDZ can be defined as the range (in terms of the power difference between DG inverter and load or load parameters) in which an islanding detection scheme under test fails to detect this condition [25]. The second one is associated with the type of loads (potential loads inside an isle), which can be modelled as a parallel RLC circuit. This circuit is primarily used because it raises more difficulties for islanding detection techniques than others. Generally, non-linear loads that 
produce current harmonics, or constant power loads do not represent difficulties for islanding detection [26].

The passive techniques are based on islanding detection through monitoring of parameters such as voltage, current, frequency and/or their characteristics.

Those techniques interrupt the inverter operation when a transition occurs beyond the limits established for these parameters. They have the advantage of not worsening the quality of power, but exhibit a considerable Non Detection Zone (NDZ). The main passive techniques are:

- Over/under-voltage and over/under-frequency [27]

- Detection of voltage and current harmonics [28].

- Detection based on state estimators [29].

The active techniques intentionally introduce disturbances at the output of the inverter to determine if they affect voltage, frequency and impedance parameters, in which case it is assumed that the grid has been disconnected and the inverter is isolated from the load.

Active techniques have the advantage of remarkably reducing or even eliminating the NDZ, but in order to achieve their purpose they may deteriorate the quality of the grid voltage or even cause instability. Among the active techniques can be found:

- Harmonic injection/detection of impedance [30].

- Sandia Frequency Shift (SFS) Sandia Voltage Shift (SVS) [31].

- Variation of active power and reactive power [32].

- General Electric Frequency Schemes (GEFS) [33].

The method used in this work is the active method based on harmonic injection. This method has the particularity of monitoring changes in the grid impedance due to the injection of a particular harmonic or a sub-harmonic [34]. It is based on the idea that when grid is connected, the impedance of the grid at the injected harmonic frequency is lower than that of the load, so that and the current produced by this harmonic flows into the grid. When the grid is disconnected, the current produced by the injected harmonic flows through the load, producing a voltage harmonic which can be detected.

In order to inject a second harmonic, the method based on PLL perturbation shown in [30] has been adopted in this work. The idea is to inject a harmonic current, in this case a second-order harmonic, to change the phase of the inverter current $\left(\cos \left(\theta_{I N V}\right)\right.$ in Fig. 1). This is achieved by injecting a sinusoidal signal synchronized with the PLL phase which forces to smoothly modify the phase of the inverter current. A feedback signal is extracted from the point common coupling voltage ( $V_{q}$ component) as a result of the injected harmonic signal. When the grid is disconnected, a high second harmonic in $V_{q}$ can be detected.

Fig. 5 shows a block diagram of the adopted anti-islanding method based on the injection of a second harmonic and on the detection of grid impedance changes.

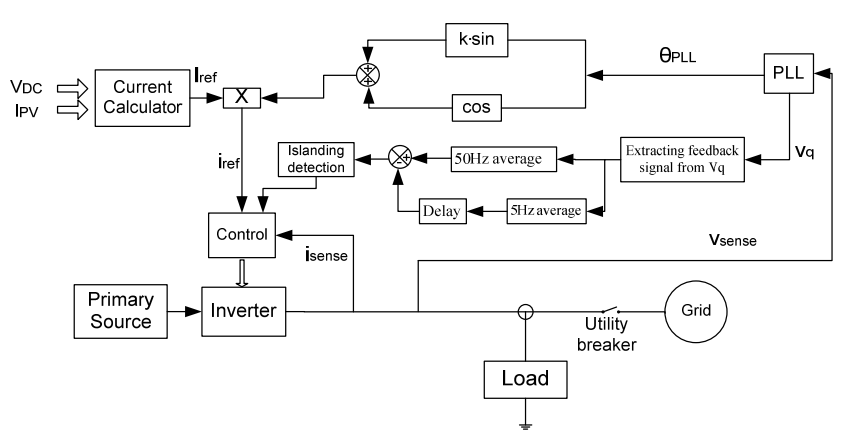

Fig. 5. Block diagram of the adopted islanding detection method.

\section{MICROINVERTER SYSTEM DESCRIPTION IN ISLAND} MODE

The control configuration proposed for the PV microinverter working in island mode is shown in Fig. 6.

In island mode and without the use of backup energy storage elements, the microinverter should deliver the amount of energy demanded by the load, supposing that the PV generation capacity is not exceeded. In that case the supplied power should be limited to the maximum available one from the source. To achieve this, in [35] it is proposed regulate the input voltage $\left(V_{g}\right)$ of the push-pull by means of a reference set by the addition of two components (see Fig. 6). The first one is the signal calculated by the maximum power point tracker, MPPT $\left(V_{\text {ref_MPPT }}\right)$, implemented by a P\&O algorithm. The second component is obtained by closing an external voltage loop, which controls the output voltage $\left(V_{D C}\right)$ of the pushpull, i.e., the DC input voltage of the inverter. Note that this voltage is usually controlled by the inverter in grid connected applications, because there is no need to regulate the inverter output AC voltage and, therefore, the inverter can adjust its input DC voltage by managing the amount of energy that is injected to the grid.

On the contrary, in island mode the inverter feeds the local loads, offering similar waveform characteristics, both in voltage and frequency, as the distribution grid. As the inverter controls its output voltage in island mode, it is obvious that it cannot also regulate its input DC voltage. Apparently, the DC-DC converter could achieve this task in a conventional way, i.e., by closing a voltage control loop of its output voltage (i.e. the inverter input voltage) around the inner current loop. However, in that case the PV panels voltage would become uncontrolled and the extracted PV energy would not be efficiently managed. Thus, the maximum power point (MPP) or another power point demanded by the loads would not be reached. With the approach proposed in [35], the push-pull converter can regulate simultaneously both its output and input voltages. The input voltage is adjusted by closing a control loop around the inner current loop, whereas the output voltage is regulated by means of an additional control loop, as it is shown in Fig. 6. It is worth pointing out that the controller of $\mathrm{V}_{\mathrm{DC}}$ in Fig. 6 is a PI one with a negative sign in cascade with an integrator.

Besides, it should be taken into account that the power provided by the microinverter is that required by the loads. 
For this reason, it is necessary to find the inverter voltage reference as a function of the active and reactive power consumed by the load. The droop method [36] is used to meet this goal.

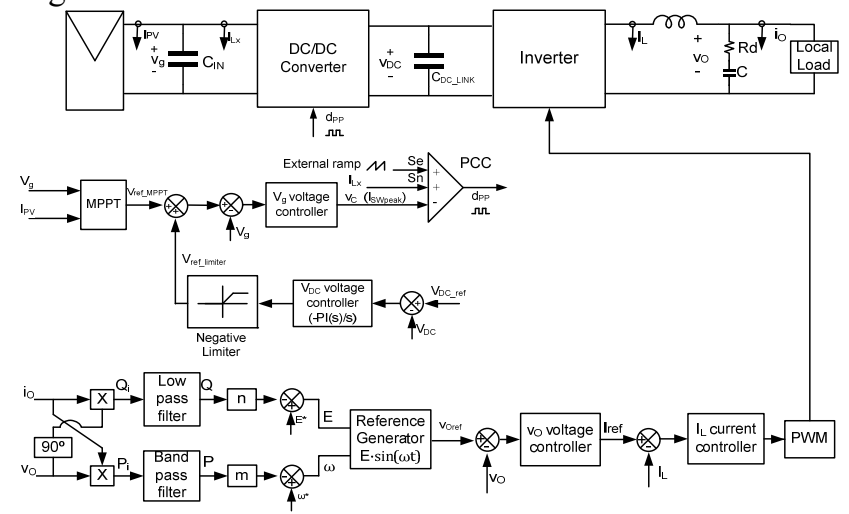

Fig. 6. Control configuration of the PV microinverter working in island mode.

Table III shows the expressions of the chosen regulators for both the inner current loops and the outer voltage loops, along with the corresponding crossover frequencies and phase margins for the microinverter in island mode. Details about the adjustment of the controllers in island mode can be found in [35], [37].

TABLE III

EXPRESSIONS OF THE CHOSEN CONTROLLERS, CROSSOVER FREQUENCIES AND PHASE MARGINS. ISLAND MODE.

\begin{tabular}{|c|c|c|c|}
\hline \multicolumn{4}{|c|}{ Push-pull } \\
\hline Controller & Expression in the continuous time & C. freq. & $\begin{array}{c}\text { P. } \\
\text { mar. }\end{array}$ \\
\hline $\begin{array}{l}\text { PWM } \\
\text { modulator } \\
\text { gain }\end{array}$ & $F_{M}=\frac{L_{X} \cdot f_{S} \cdot N^{2}}{(1-2 \cdot D) \cdot V_{g} \cdot R_{i}+L_{X} \cdot S_{e} \cdot N^{2}}$ & $1.42 \mathrm{kHz}$ & $77.7^{\circ}$ \\
\hline $\begin{array}{l}\mathrm{R}_{\mathrm{i}} \\
\mathrm{S}_{\mathrm{e}}\end{array}$ & $0.015 \Omega$ & & \\
\hline $\mathrm{S}_{\mathrm{e}}$ & $2181 \mathrm{~V} / \mathrm{s}$ & & \\
\hline $\begin{array}{l}\text { Push-pull } \\
\text { input } \\
\text { voltage } \\
\text { controller }\end{array}$ & $-1 \cdot\left(k_{p}+\frac{k_{i}}{s}\right)=-1 \cdot\left(3.75+\frac{750}{s}\right)$ & $199 \mathrm{~Hz}$ & $90.2^{\circ}$ \\
\hline $\begin{array}{l}\text { DC_link } \\
\text { voltage } \\
\text { controller }\end{array}$ & $-\frac{1}{s} \cdot\left(K_{p}+\frac{K_{i}}{s}\right)=-\frac{1}{s} \cdot\left(30299+\frac{5756.81}{s}\right)$ & $50 \mathrm{~Hz}$ & $76.2^{\circ}$ \\
\hline \multicolumn{4}{|c|}{ Inverter } \\
\hline $\begin{array}{l}\text { Current } \\
\text { controller }\end{array}$ & $k_{p}+\frac{k_{n} \cdot B_{n} \cdot s}{s^{2}+B_{n} \cdot s+\left(\omega_{n}^{2}\right)}=1.04+\frac{100 \cdot(2 \pi) \cdot s}{s^{2}+2 \pi \cdot s+(100 \pi)^{2}}$ & $1.6 \mathrm{kHz}$ & $81.2^{\circ}$ \\
\hline $\begin{array}{l}\text { Output } \\
\text { voltage } \\
\text { controller }\end{array}$ & $K_{p}+\frac{K_{i}}{s+\delta}=0.048+\frac{1384}{s+10}$ & $502 \mathrm{~Hz}$ & $65.2^{\circ}$ \\
\hline
\end{tabular}

In order to establish the inverter voltage reference for the voltage controller, droop schemes [38] are applied. Such methods are based on the well-known concept of the power flow management in large-scale AC generators, which lies in reducing the frequency when the output power is increased [39].

A scheme that represents the power flow through a transmission line is shown in Fig. 7.

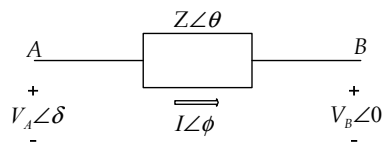

Fig. 7. Power flow through a transmission line.

where $Z$ and $\theta$ represent the magnitude and phase of the output impedance, respectively, and $\delta$ represents the phase of the voltage between points $A$ and $B$.

When the impedance of the transmission line has an inductive behavior $(Z=j X)$, the active power $(P)$ and reactive power $(Q)$ supplied to the load can be expressed as:

$$
\begin{gathered}
P=\frac{V_{A} \cdot V_{B}}{X} \sin \delta \\
Q=\frac{V_{A} \cdot V_{B} \cdot \cos \delta-V_{B}^{2}}{X}
\end{gathered}
$$

From (1) y (2), and considering small a phase difference between $V_{A}$ y $V_{B}$ (i.e. a small $\delta$ ), it can be observed that $P$ has a strong dependence on the angle $\delta$, whereas $Q$ depends on the amplitude difference between $V_{A}$ y $V_{B}$.

The adopted droop scheme is depicted in Fig. 8.
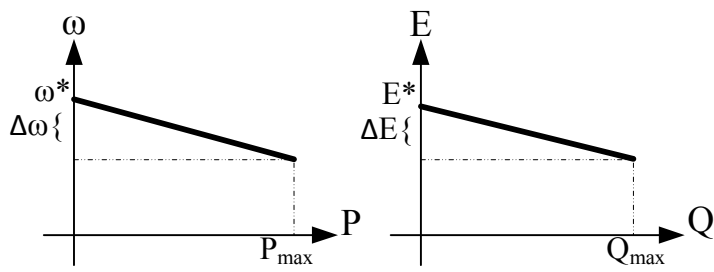

Fig. 8. Static droop characteristics for inductive output impedance.

The frequency $(\omega)$ and the voltage amplitude $(E)$ of the inverter voltage reference can be expressed through equations (3) and (4).

$$
\omega=\omega^{*}-m \cdot P
$$

$$
E=E^{*}-n \cdot Q
$$

Being $\omega^{*}$ and $E^{*}$ the frequency and amplitude of the inverter reference voltage at not load, whereas $m$ and $n$ represent the frequency and amplitude droop coefficients, respectively.

The coefficients $m$ and $n$ can be chosen as in the conventional droop method to ensure steady state control objectives [40] as follows:

$$
\begin{aligned}
& m=\frac{\Delta \omega}{P_{\max }} \\
& n=\frac{\Delta E}{Q_{\max }}
\end{aligned}
$$

, where $P_{\max }$ and $Q_{\max }$ are the maximum active and reactive powers that can be delivered by the inverter and $\Delta \omega$ and $\Delta E$ are the maximum frequency and output-voltage amplitude deviations allowed. Hence, these two parameters can be fixed by the designer taking into account the tradeoff between the 
power sharing accuracy and the frequency and amplitude deviation. In this case $m$ and $n$ were set to 0.001 .

The active power $(P)$ can be obtained by means of low pass filtering the inverter instantaneous output power. It is necessary take into account that the conventional droop scheme cannot satisfy the need for synchronization with other inverters or with the grid due to the frequency variation of the inverters, which produce a phase deviation. To obtain the required performance it is necessary to eliminate the DC component of the active power. In [41] is proposed include a high pass filter in series with the low pass filter. Therefore the resulting filter is a band pass filter.

The reactive power (Q) is calculated in a similar way. However, in this case the output voltage measurement is delayed $90^{\circ}$ and a low pass filter is used. The expressions of the chosen band pass filter, $\operatorname{BPF}(\mathrm{s})$, and of the low pass filter, $\operatorname{LPF}(\mathrm{s})$, are presented in equations (7) and (8), respectively.

$$
\begin{gathered}
B P F(s)=\frac{s}{0.3183 \cdot s+1} \cdot \frac{1}{31.83 \cdot 10^{-3} \cdot s+1} \\
\operatorname{LPF}(s)=\frac{1}{31.83 \cdot 10^{-3} \cdot s+1}
\end{gathered}
$$

\section{TRANSITION BETWEEN OPERATION MODES}

In this section it is provided a brief description of the control configuration changes that occur in the transition between operation modes.

\section{A. Transition From Grid Connected Mode to Island Mode.}

In the transition from the grid connected mode to island mode it is necessary to change the voltage controller of the inverter, because in grid connected mode the voltage loop controls the $\mathrm{DC}$ link voltage, $\mathrm{V}_{\mathrm{DC}}$, whereas in island mode the load voltage, $\mathrm{V}_{\mathrm{O}}$, is controlled. Furthermore, the reference for the voltage controller in island mode is provided by the droop scheme, whereas it is a constant value for the grid connected mode. In the same way, the push-pull voltage controller changes its control configuration to regulate the DC_link voltage and adjust the input voltage to the push-pull.

In order to avoid abrupt transitions from one operation mode to the other, the final conditions of the controllers in a particular mode must be equal to the initial conditions of the controller in the new mode. It should be highlighted that the same output current controller for both push-pull and inverter are used in both operation modes [42].

\section{B. Transition From Island Mode to Grid Connected Mode.}

When the microinverter is operating in island mode and the grid is reconnected it is possible to interconnect the microinverter to the grid. This is done by synchronizing the microinverter output phase with the grid phase. This action is accomplished by measuring the corresponding phases and doing their difference near to zero using a synchronization loop [41]. Fig. 9 shows the synchronization loop.

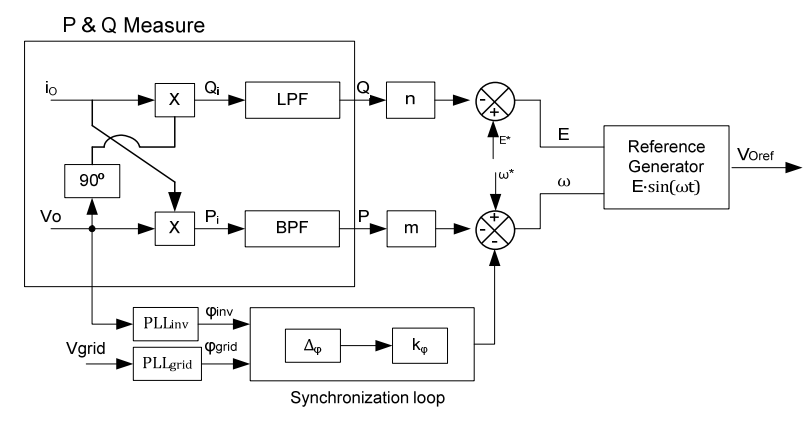

Fig. 9. Block diagram of the droop scheme with synchronization loop.

From Fig. 9 it can be found the expression of the inverter output frequency during the synchronization with the grid:

$$
\omega=\omega^{*}-m \cdot(P \cdot B P F(s))-k_{\varphi} \cdot \Delta_{\varphi}
$$

, where $\Delta_{\varphi}$ is the phase difference (in radians) between the microinverter and the grid, and $k_{\varphi}$ is the frequency proportional constant. For this work the phase measurement was performed by means of two dqPLL. Once the angular difference becomes zero through the action of the synchronization loop, the switch reconnects the microinverter to the grid. A value of $k_{\varphi} \approx 0.2$ was chosen to ensure a fast and suitable synchronization between the inverter and the grid without affecting the system stability.

\section{SimULATION RESULTS}

The results of the PV microinverter operating in grid connected mode and in island mode are shown in the following. The system has been simulated by means of PSIM 7.0.5 simulation software [43]. Additionally, it has been considered a grid inductance $\left(L_{g}\right)$ of $1.91 \mathrm{mH}$, i.e. $10 \%$ of the inverter output inductor and $0,2 \%$ of the base inductance of a $180 \mathrm{~W}$ PV inverter.

Fig. 10 shows the main waveforms of the microinverter connected to the grid in the case of step variations of the current delivered by the PV source, $I_{p v}$. It is worth pointing out that irradiance variations on the PV panels cannot provoke so quick $I_{p v}$ variations in a real case, but this simulation is a tough stability test for the microinverter control loops. In the experimental results to be shown in section VII, those $I_{p v}$ steps can be achieved by means of a DC programmable source. In Fig. 10 it is observed that under variations of the PV source current, the output current is properly controlled, allowing the power injection to the grid according to the maximum available power. 


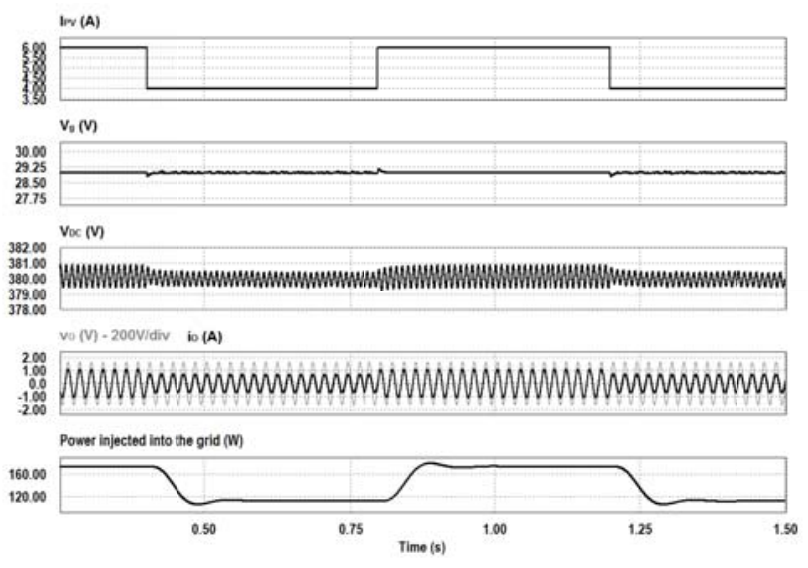

Fig. 10. Main waveforms in grid connected mode.

Fig. 11 shows the waveforms when the grid is disconnected from the microinverter and from a $440 \Omega$ resistive load and the waveforms after the subsequent microinverter control reconfiguration from grid connected mode to island mode. The upper waveform signals the islanding instant, going from high to low level when the grid is disconnected.

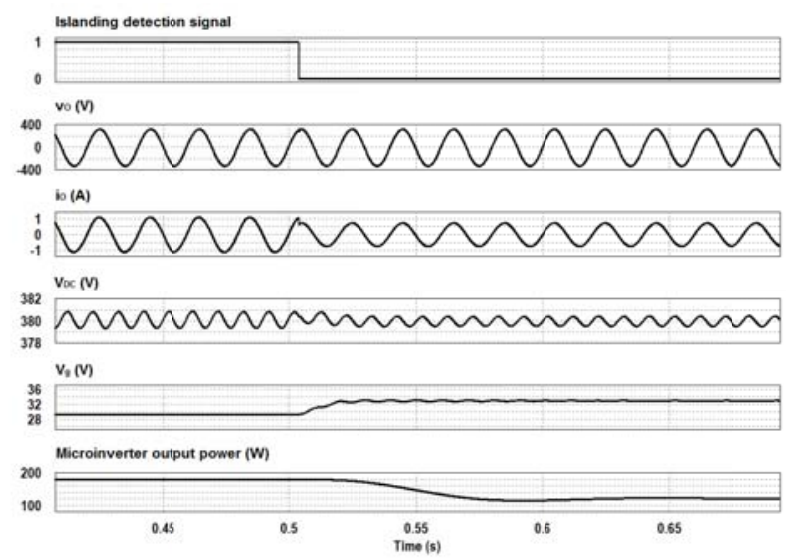

Fig. 11. Main waveforms during the microinverter control reconfiguration from grid connected mode to island mode.

As it can be observed from Fig. 11, the microinverter injects the maximum available power before the disconnection of the grid $(180 \mathrm{~W})$. When the grid is disconnected, the control scheme changes to island mode, feeding the microinverter a resistive load that absorbs $120 \mathrm{~W}$ at $230 \mathrm{Vrms}$. It can be observed that the PV panel voltage, $\mathrm{V}_{\mathrm{g}}$, increases in order to leave the panel MPP.

Fig. 12 shows the waveforms during the reconnection of the microinverter to the grid, and the subsequent microinverter control reconfiguration from island mode to grid connected mode.

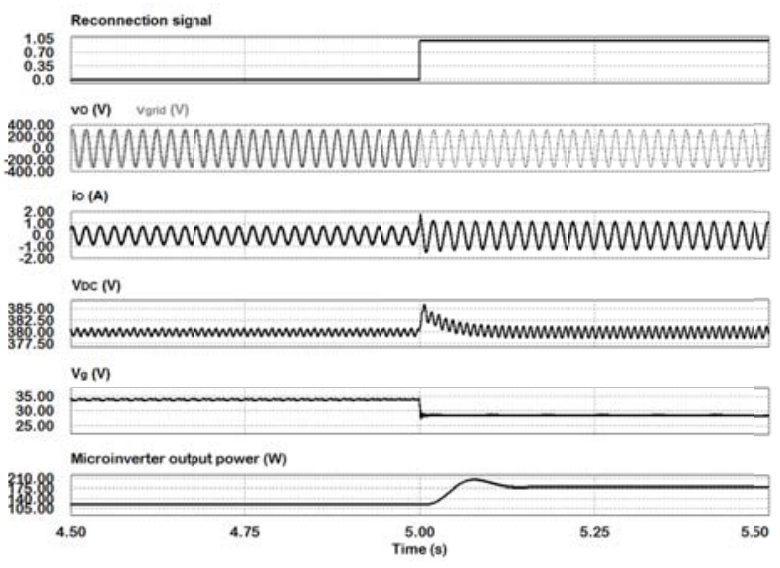

Fig. 12. Main waveforms during the microinverter control reconfiguration from island mode to grid connected mode.

Note that the reconnection transient exhibits no oscillations, and the controllers are adjusted quickly to operate in grid connection mode.

Fig. 13 shows the main waveforms of two equal microinverters operating in parallel when the disconnection between the grid and the microinverters takes place. In this situation the microinverters have a load distribution defined by their corresponding $m$ and $n$ slopes, which agree in this case. The upper waveform signals the islanding event.

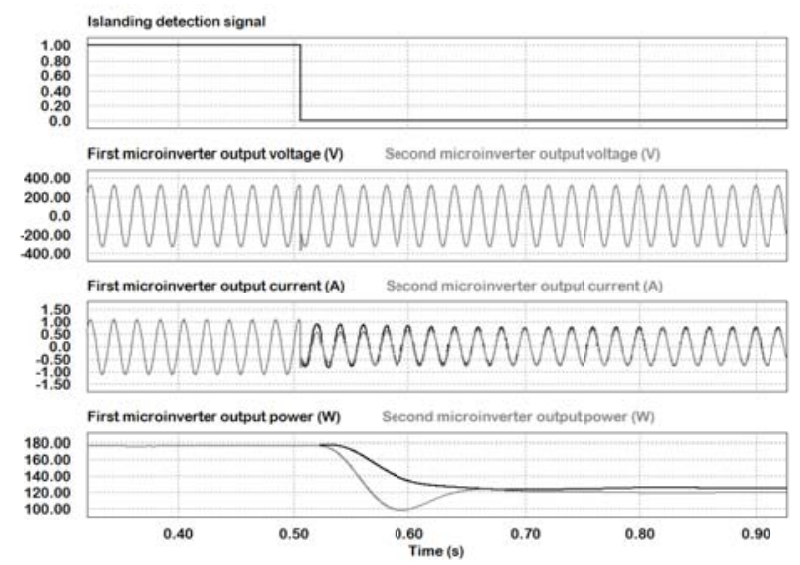

Fig. 13. Main waveforms of two inverters connected in parallel in the transition from the grid connected mode to the island mode.

Fig. 14 shows the main waveforms of two equal microinverters operating in parallel when the reconnection between the microinverters and the grid takes place. In $\mathrm{t}=0.4$ sec. the grid voltage comes back and the synchronization algorithm starts to synchronize $v_{O 1}, v_{O 2}$ and $v_{\text {grid }}$. In $\mathrm{t}=1 \mathrm{sec}$. the grid circuit breaker is closed. The transition from island mode to grid mode is very smooth, without oscillations that can damage in the system. 


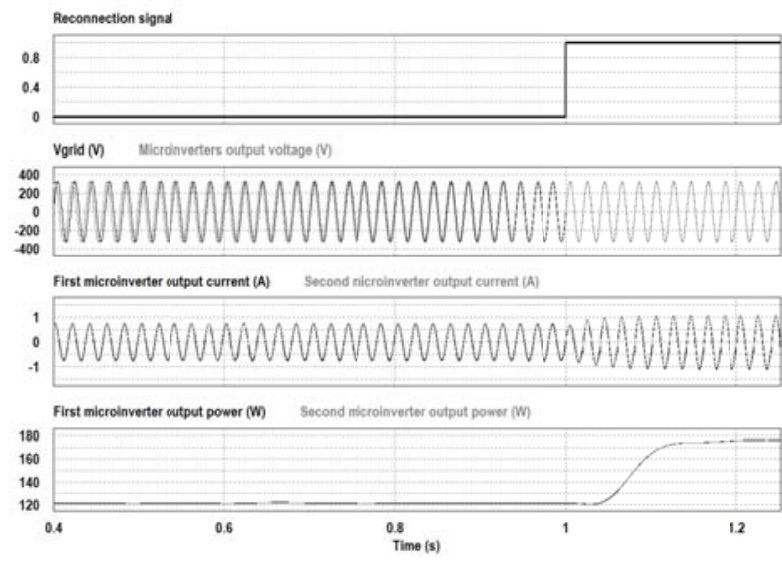

Fig. 14. Main waveforms of two inverters connected in parallel in the transition from the island mode to the grid connected mode.

\section{EXPERIMENTAL RESULTS}

Experimental tests have been performed in order to show the feasibility of the proposed controllers. The hardware setup shown in Fig. 15 is based on an $180 \mathrm{~W}$ microinverter whose characteristics have been summarized in Table I, whereas the adjustment of the controllers has been described in previous sections. A TMS320F28335 Digital Signal Processor (DSP) performs the inner current loop and an outer PI controller that ensures voltage regulation for both grid mode and island mode, corresponding to the inverter control. The droop schemes of the inverter and the voltage controller of the push-pull converter are also running on the DSP. The sampling frequency is $40 \mathrm{kHz}$ and the Tustin method has been chosen for the controllers discretization. The DSP control also includes a PLL block in order to synchronize the microinverter with the grid. The experimental results have been obtained by connecting a programmable DC power supply AMREL SPS800-12-D-013 to the microinverter input.

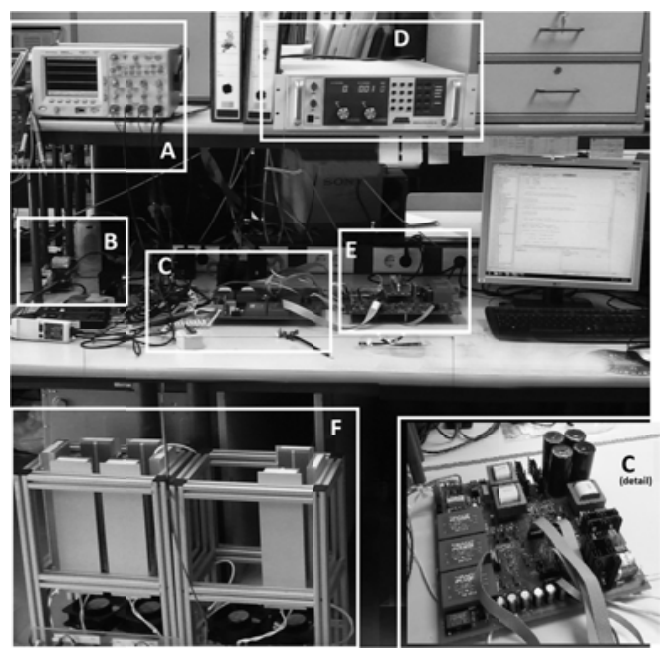

Fig. 15. Laboratory setup to test the reconfigurable control scheme for a microinverter working in both grid connected and island modes. A. Oscilloscope, B. Point of common coupling, C.

Microinverter, D. DC power supply AMREL SPS800-12-D-013, E. TMS320F28335 Digital Signal Processor, and F. Loads.
Fig. 16 shows a large-signal stability test of the microinverter in grid connected mode. The DC power supply has been configured as a current source that undergoes a sudden step in $I_{P V}$ from $4 \mathrm{~A}$ to $6 \mathrm{~A}$ and back to $4 \mathrm{~A}$. The output voltage of the DC supply (microinverter input voltage) is controlled by the push-pull to a constant value $V_{D C}=28 \mathrm{~V}$. The test is useful to demonstrate the robustness of the dynamics of the proposed control structure to fast transients, although the variations of $\mathrm{I}_{\mathrm{PV}}$ are not so fast in a real PV panel. It can be observed from Figure 16 that the dynamic response of both the grid injectied current and of $V_{D C}$ is stable and well damped.

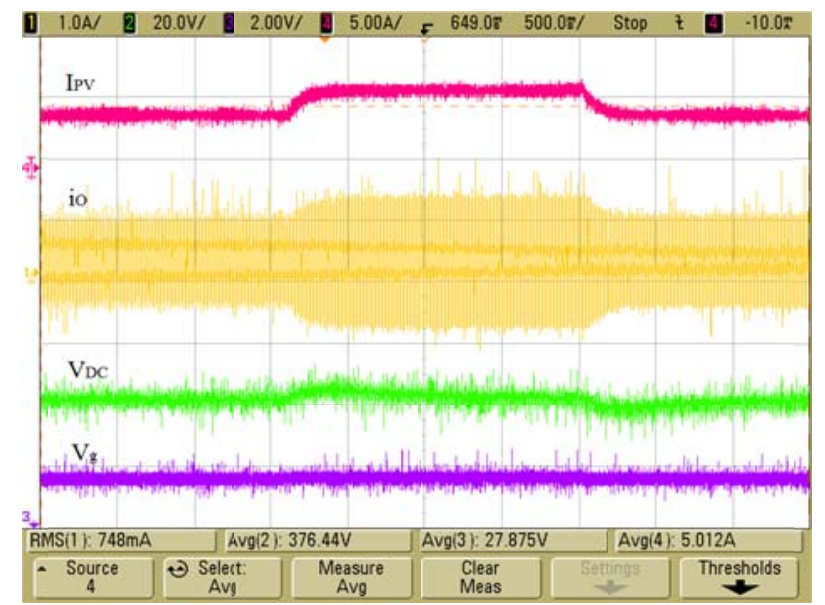

Fig. 16. Large-signal response of the microinverter. Input current step $\mathrm{I}_{\mathrm{PV}}$ (first trace, $5 \mathrm{~A} / \mathrm{div}$ ) from $4 \mathrm{~A}$ to $6 \mathrm{~A}$ and back to $4 \mathrm{~A}$. $\mathrm{i}_{\mathrm{O}}$ (second trace, $1 \mathrm{~A} /$ div). $\mathrm{V}_{\mathrm{DC}}$ (third trace, $20 \mathrm{~V} /$ div). $\mathrm{V}_{\mathrm{g}}$ (fourth trace, $2 \mathrm{~V} /$ div). Time scale $=500 \mathrm{~ms} /$ div.

Fig. 17 shows the transition from grid connected mode to island mode (start of the islanding situation) with a local load of $350 \Omega(151 \mathrm{~W}$ at $230 \mathrm{Vrms})$. As it can be observed, the microinverter can, with a smooth transient, switch from grid connected mode to island mode while regulating the output voltage quickly to the nominal operating range. In grid connected mode the microinverter output current follows a reference that allows to inject the maximum available power from the programmable DC source, whereas in island mode the output current follows the reference imposed by the droop schemes (load). In this case the resistive load absorbs a smaller power $(151 \mathrm{~W})$ than that injected to the grid before islanding $(180 \mathrm{~W})$. Additionally, the microinverter input voltage is adjusted by a perturb and observe (P\&O) MPPT algorithm [14] to follow the load power consumption.

Fig. 18 shows a detail of Fig. 17, in which a good transient response between both operation modes is observed. 


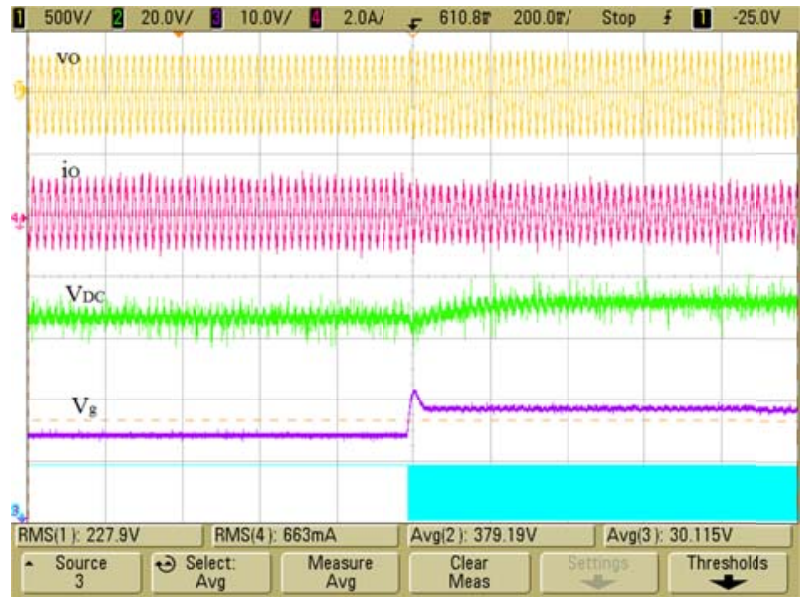

Fig. 17. Transient response of the transition from grid connected mode to island mode. $\mathrm{v}_{\mathrm{O}}$ (first trace, $500 \mathrm{~V} / \mathrm{div}$ ). $\mathrm{i}_{\mathrm{O}}$ (second trace, $2 \mathrm{~A} /$ div). $\mathrm{V}_{\mathrm{DC}}$ (third trace, $20 \mathrm{~V} /$ div). $\mathrm{V}_{\mathrm{g}}$ (fourth trace, $10 \mathrm{~V} /$ div). Islanding detection signal (fifth trace). Time scale $=200 \mathrm{~ms} / \mathrm{div}$.

It is observed from Fig. 17 that the steady state value of $V_{D C}$ in island mode is slightly higher $(385 \mathrm{~V})$ than in grid connected mode $(380 \mathrm{~V})$. This small difference is due to slight differences in the $V_{D C}$ reference imposed to the inverter and to the DC-DC converter in the experimental prototype.

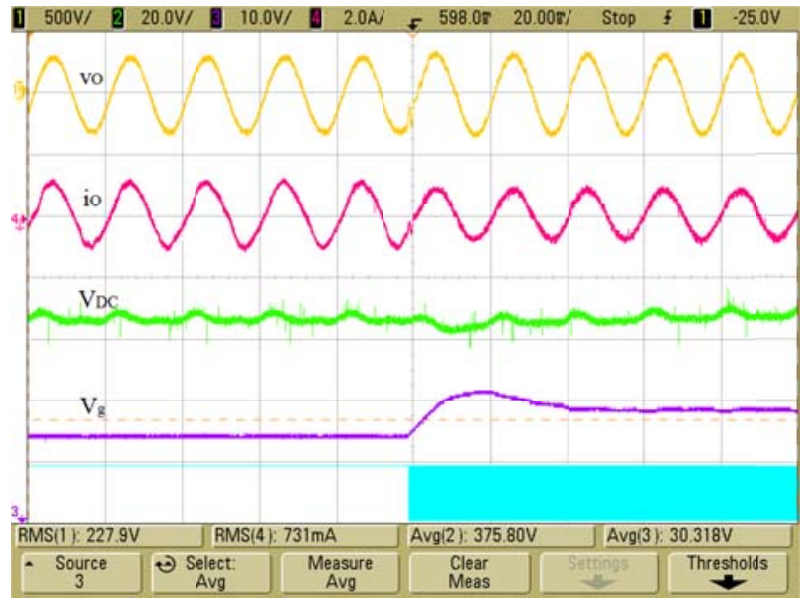

Fig. 18. Detail of the transient response of the transition from grid connected mode to island mode. $\mathrm{v}_{\mathrm{O}}$ (first trace, $500 \mathrm{~V} / \mathrm{div}$ ). $\mathrm{i}_{\mathrm{O}}$ (second trace, $2 \mathrm{~A} / \mathrm{div}$ ). $\mathrm{V}_{\mathrm{DC}}$ (third trace, $20 \mathrm{~V} / \mathrm{div}$ ). $\mathrm{V}_{\mathrm{g}}$ (fourth trace,

$10 \mathrm{~V} / \mathrm{div}$ ). Islanding signal (fifth trace). Time scale $=20 \mathrm{~ms} / \mathrm{div}$.

Fig. 19 depicts the transient response of the microinverter for resistive load step changes from $120 \mathrm{~W}$ to $182 \mathrm{~W}$ and back to $120 \mathrm{~W}(440 \Omega$ to $290 \Omega$ and back to $440 \Omega$ ) in island mode. It is shown that when the microinverter works with the droop schemes the load changes do not affect significantly the microinverter operation, whereas the transients are smooth.

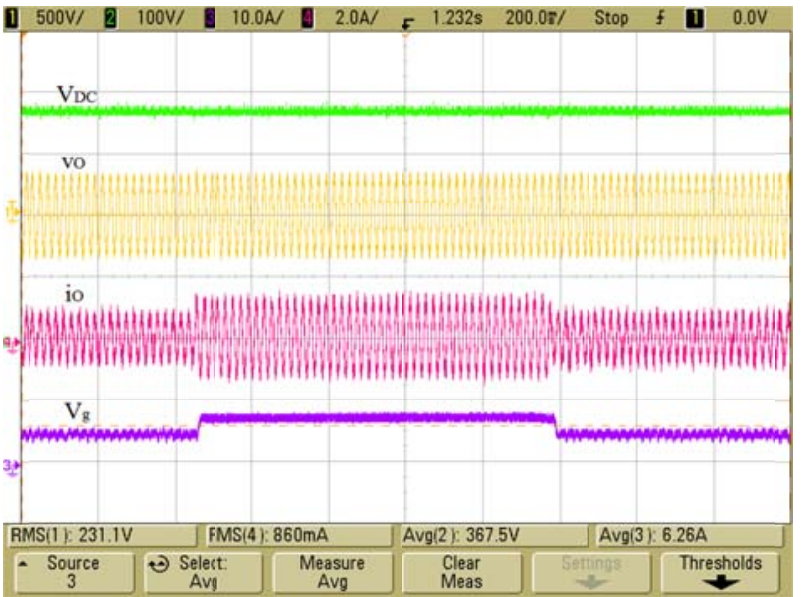

Fig. 19. Transient response for load step changes in island mode $\mathrm{V}_{\mathrm{DC}}$ (first trace, $100 \mathrm{~V} / \mathrm{div}$ ). $\mathrm{v}_{\mathrm{O}}$ (second trace, $500 \mathrm{~V} / \mathrm{div}$ ). $\mathrm{i}_{\mathrm{O}}$ (third trace, $2 \mathrm{~A} / \mathrm{div}) . \mathrm{V}_{\mathrm{g}}$ (fourth trace, $\left.10 \mathrm{~V} / \mathrm{div}\right)$. Time scale $=200 \mathrm{~ms} / \mathrm{div}$.

Fig. 20 shows the synchronization between the microinverter output voltage and the grid voltage when the grid is reconnected. When both phases match the circuit breaker can be reclosed.
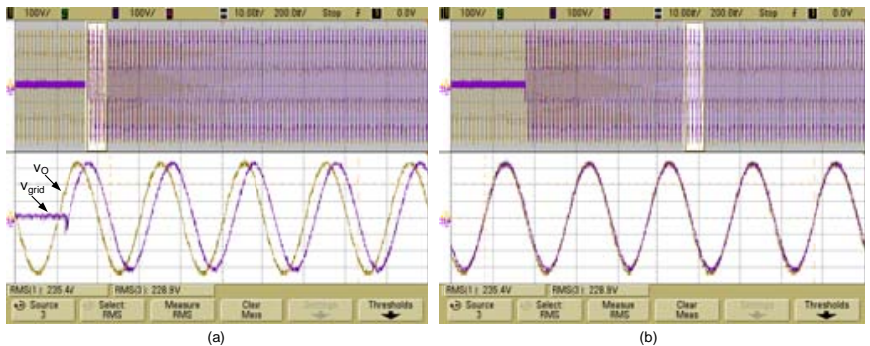

Fig. 20. Microinverter output voltage synchronization with the grid voltage (top, 100V/div). Detail of the synchronization signals (a) Start of the synchronization and (b) Synchronized signals. Time scale $=2010 \mathrm{~ms} /$ div .

Fig. 21 shows a smooth transition between island mode and grid connected mode. Once the grid and the inverter voltages are synchronized, the grid circuit breaker is reclosed. This transition has no significant voltage or current transients. The microinverter is loaded with $150 \mathrm{~W}$ in island mode. After the transition, the microinverter injects the power supplied by the programmable DC source into the grid, in this case $180 \mathrm{~W}$. 


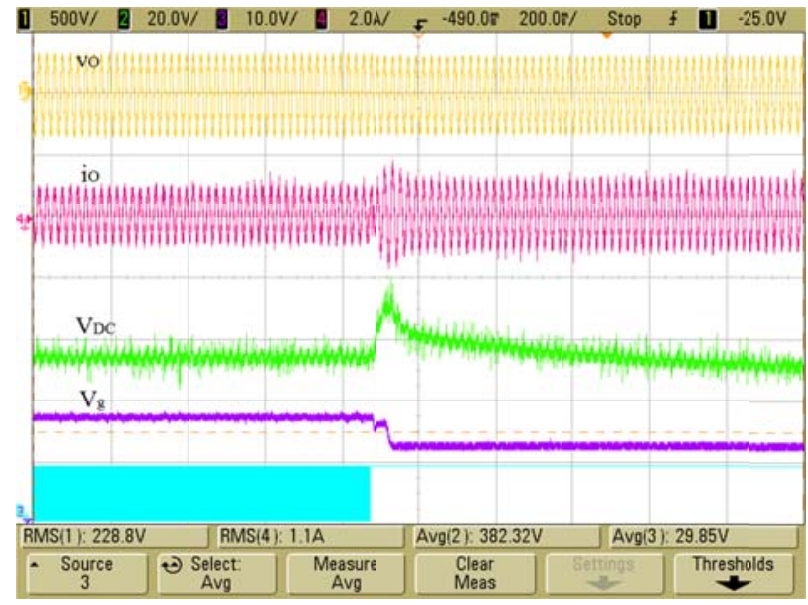

Fig. 21. Transient response for the transition from island mode to grid connected mode. $\mathrm{v}_{\mathrm{O}}$ (first trace, $500 \mathrm{~V} / \mathrm{div}$ ). $\mathrm{i}_{\mathrm{O}}$ (second trace, $2 \mathrm{~A} /$ div). $\mathrm{V}_{\mathrm{DC}}$ (third trace, $20 \mathrm{~V} / \mathrm{div}$ ). $\mathrm{V}_{\mathrm{g}}$ (fourth trace, $10 \mathrm{~V} / \mathrm{div}$ ).

Reconnection signal (fifth trace). Time scale $=200 \mathrm{~ms} / \mathrm{div}$.

Fig. 22 shows a detail of Fig 21, in which a good transient response of the transition from island mode to grid connected mode, is observed.

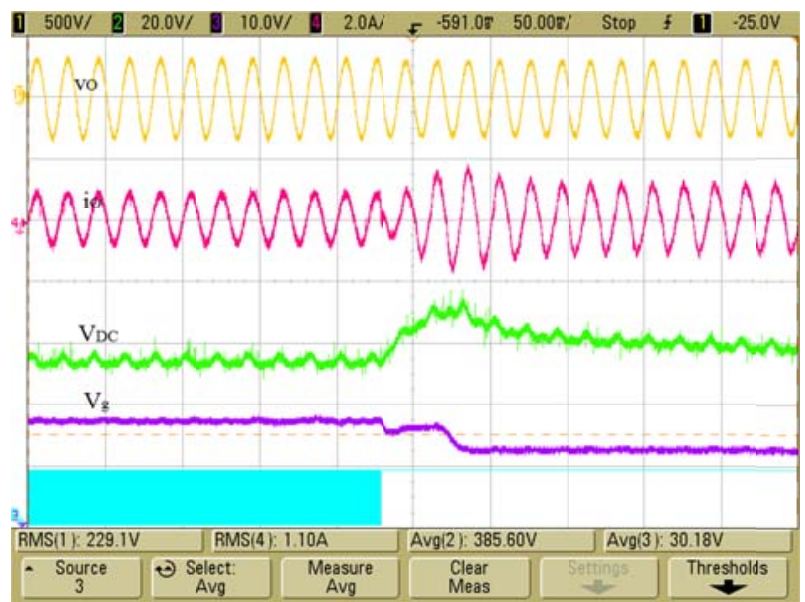

Fig. 22. Detail of the transient response of the transition from island mode to grid connected mode. $v_{O}$ (first trace, $500 \mathrm{~V} / \mathrm{div}$ ). $\mathrm{i}_{\mathrm{O}}$ (second trace, $2 \mathrm{~A} /$ div). $\mathrm{V}_{\mathrm{DC}}$ (third trace, 20V/div). $\mathrm{V}_{\mathrm{g}}$ (fourth trace, $10 \mathrm{~V} / \mathrm{div}$ ). Reconnection signal (fifth trace). Time scale $=50 \mathrm{~ms} / \mathrm{div}$.

\section{CONCLUSIONS}

The control algorithms for grid connected PV microinverters have been developed and refined over the time, being highly reliable for grid connected operation. The main contribution of this paper is to provide those microinverters with the additional functionality of working in island mode without changing their control algorithms for grid connected mode. It is proposed to reconfigure the microinverter control in island mode to work as a voltage source using droop schemes. This paper is focused on PV generation systems based on a double power conversion structure (DC-DC converter + inverter), although the reconfiguration proposal could be applied to other topologies.
The control structures for both PV microinverter operation modes are presented in this paper. In the grid connected mode the inverter controls its input DC voltage and its output current, working as a current source in phase with the grid voltage, injecting the available PV power to the grid, whereas the DC-DC converter connected between the PV panel and the inverter controls the microinverter input voltage (i.e. the PV panel voltage) achieving the MPP tracking. This is the operation mode of most commercial PV grid connected microinverters based on a double power conversion structure. In the island mode the same current controller is used for the inverter, but its voltage controller is reconfigured in order to regulate the inverter output voltage. Besides, in that operation mode the DC-DC converter controls its input voltage, whereas its output voltage (i.e. the inverter input voltage) is regulated by means of an additional control loop. In that way proper voltage and frequency levels are provided to the local loads. The reference for the inverter voltage loop is obtained by means of droop schemes. Such schemes allow the inverter to work in grid isolated mode. The reconfiguration of the controllers from one mode to the other one is validated through simulation. Finally, experimental results have been presented in order to validate the proposed approach, showing a proper reconfiguration of the controllers both when the islanding situation appears and when the grid is reconnected.

\section{ACKNOWLEDGEMENTS}

This work was supported by the Spanish Ministry of Science and Innovation under Grant ENE2009-13998-C0202 .

\section{REFERENCES}

[1] REN21 Steering Committee, "Renewable 2009, Global Status Report", Worldwatch Institute Washington., DC, 2009.

[2] H.B Puttgen, P.R. MacGregor, and F.C. Lambert, "Distributed generation: Semantic hype or the dawn of a new era?", IEEE Power and Energy Magazine, vol.1, no.1, pp. 22-29, Jan-Feb 2003.

[3] R.H. Lasseter, "White paper on integration of distributed energy resources. The CERTS microgrid concept", Consortium for Electric Reliability Technology Solutions, pp. 1-27, 2002.

[4] J.M. Guerrero, J.C. Vasquez, J. Matas, M. Castilla, L.G. de Vicuna, "Control Strategy for Flexible Microgrid Based on Parallel LineInteractive UPS Systems", IEEE Trans. on Industrial Electronics, vol.56, no.3, pp.726-736, March 2009.

[5] J.C. Vasquez, J.M. Guerrero, A. Luna, P. Rodriguez, R, Teodorescu, "Adaptive Droop Control Applied to Voltage-Source Inverters Operating in Grid-Connected and Islanded Modes," IEEE Trans. on Industrial Electronics, vol.56, no.110, pp.4088-4096, Oct. 2009.

[6] Yaow-Ming Chen, Hsu-Chin Wu, Yung-Chu Chen, Kung-Yen Lee, Shian-Shing Shyu, "The AC Line Current Regulation Strategy for the Grid-Connected PV System," IEEE Trans. on Power Electronics, vol.25, no.1, pp.209-218, Jan. 2010.

[7] K. Jaehong, J.M. Guerrero, $\mathbb{P}$. Rodriguez, R. Teodorescu, N. Kwanghee, "Mode Adaptive Droop Control With Virtual Output Impedances for an Inverter-Based Flexible AC Microgrid," IEEE Trans. on Power Electronics, vol.26, no.3, pp.689-701, March 2011.

[8] I.J. Balaguer, L. Qin, Y. Shuitao, U. Supatti, Fang Zheng Peng, "Control for Grid-Connected and Intentional Islanding Operations of Distributed Power Generation," IEEE Trans. on Industrial Electronics, vol.58, no.1, pp.147-157, Jan. 2011.

[9] C. Chien-Liang, W. Yubin, L. Jih-Sheng, Yuang-Shung Lee; D. Martin, "Design of Parallel Inverters for Smooth Mode Transfer Microgrid Applications," IEEE Transactions on Power Electronics, vol.25, no.1, pp.6-15, Jan. 2010.

[10] K. Hyosung, Y. Taesik, C. Sewan, "Indirect Current Control Algorithm for Utility Interactive Inverters in Distributed Generation Systems," 
IEEE Transactions on Power Electronics, vol.23, no.3, pp.1342-1347, May 2008.

[11] M.A. Hassan, M.A. Abido, "Optimal Design of Microgrids in Autonomous and Grid-Connected Modes Using Particle Swarm Optimization," IEEE Transactions on Power Electronics, vol.26, no.3, pp.755-769, March 2011.

[12] N. Mohan, T. Undeland, W. Robbins, "Power electronics: converters, applications, and design", John Wiley \& Sons, 1995.

[13] Guoqiao Shen, Xuancai Zhu, Jun Zhang, and Dehong Xu, "A New Feedback Method for PR Current Control of LCL-Filter-Based GridConnected Inverter," IEEE Trans. on Industrial Electronics, vol.57, no.6, pp.2033-2041, June 2010.

[14] N. Femia, G. Petrone, G. Spagnuolo, and M. Vitelli, "A Technique for Improving P\&O MPPT Performances of Double-Stage Grid-Connected Photovoltaic Systems," IEEE Trans. on Industrial Electronics, vol.56, no.11, pp.4473-4482, Nov. 2009.

[15] D.M. Sable, R.B. Ridley, "Comparison of performance of single-loop and current-injection control for PWM converters that operate in both continuous and discontinuous modes of operation", IEEE Trans. on Power Electronics, vol.7, no.1, pp.136-142, Jan 1992.

[16] G. Garcerá, R. González-Medina, E. Figueres, J. Sandia, "Dynamic modeling of DC-DC converters with peak current control in doublestage photovoltaic grid-connected inverters", International Journal of Circuit Theory and Applications, DOI: 10.1002/cta.756. Published Online January 2011 at wileyonlinelibrary.com. In press, 2011.

[17] M. P. Kazmierkowski, R. Krishnan, and F. Blaabjerg, Control in power electronics, Academic Press, London, 2002.

[18] IEEE recommended practice for grid interface of photovoltaic (PV) systems, IEEE Std. 929, 2000.

[19] M. Ciobotaru, R. Teodorescu, F. Blaabjerg, "Control of single-stage single-phase PV inverter," IEEE European Conference on Power Electronics and Applications, pp.-P.10, 2005

[20] M. Ciobotaru, R. Teodorescu, and F. Blaabjerg, "A new single phase PLL structure based on second order generalized integrator," in Record of IEEE PESC 2006, Jeju, Korea, p. 1511-1516.

[21] N.A. Ninad, L.A.C. Lopes, "Operation of Single-phase Grid-Connected Inverters with Large DC Bus Voltage Ripple," IEEE Electrical Power Conference, EPC 2007, pp.172-176, 25-26 Oct. 2007.

[22] A. Pigazo, M. Liserre, R.A. Mastromauro, V.M. Moreno, and A. Dell'Aquila, "Wavelet-Based Islanding Detection in Grid-Connected PV Systems," IEEE Trans. on Industrial Electronics, vol.56, no.11, pp.4445-4455, Nov. 2009.

[23] L. Soo-Hyoung, and P. Jung-Wook, "New Islanding Detection Method for Inverter-Based Distributed Generation Considering Its Switching Frequency," IEEE Trans. on Industry Applications, vol.46, no.5, pp.2089-2098, Sept.-Oct. 2010.

[24] P. Mahat, Zhe Chen, and B. Bak-Jensen, "Review of islanding detection methods for distributed generation," Third International Conference on Electric Utility Deregulation and Restructuring and Power Technologies, pp.2743-2748, China, 6-9 April 2008.

[25] F. De Mango, M. Liserre, A.D. Aquila, and A. Pigazo, "Overview of Anti-Islanding Algorithms for PV Systems. Part I: Passive Methods,” Proc. of the 12th International Conference on Power Electronics and Motion Control EPE-PEMC, pp.1878-1883, Slovenia, 2006.

[26] V. Task, "Evaluation of islanding detection methods for photovoltaic utility interactive power systems," Tech. Rep. IEAPVPS T5-09:2002, March 2002

[27] H.H Zeineldin, and J.L. Kirtley, "A Simple Technique for Islanding Detection With Negligible Nondetection Zone," IEEE Transactions on Power Delivery, vol.24, no.2, pp.779-786, April 2009.

[28] S. Jang, and K. Kim, "An islanding detection method for distributed generations using voltage unbalance and total harmonic distortion of current," IEEE Trans. on Power Delivery, 2004, vol. 19, no. 2, pp. 745 752 .

[29] M. Liserre, A. Pigazo, A. Dell'Aquila, V.M. Moreno, "An AntiIslanding Method for Single-Phase Inverters Based on a Grid Voltage Sensorless Control," IEEE Trans. on Industrial Electronics, vol. 53, No. 5, pp. 1418-1426, 2006.

[30] M. Ciobotaru, V.G. Agelidis, R. Teodorescu, and F. Blaabjerg, "Accurate and Less-Disturbing Active Antiislanding Method Based on PLL for Grid-Connected Converters," IEEE Trans. Power Electron., vol.25, no.6, pp.1576-1584, June 2010.
[31] X. Wang, W. Freitas, W. Xu, and V. Dinavahi, "Impact of DG Interface Controls on the Sandia Frequency Shift Antiislanding Method," IEEE Trans. on Energy Conversion, vol. 22, vo. 3, pp. 792 - 794, 2007.

[32] C. Jeraputra, and P.N. Enjeti, "Development of a robust anti-islanding algorithm for grid interconnection of distributed fuel cell powered generation," IEEE Trans. on Power Electronics, vol.19, no.5, pp. 1163 $1170,2004$.

[33] S. Huili, L.A.C. Lopes and L. Zhixiang, "Analysis and comparison of islanding detection methods using a new load parameter space," Proc. of the 30th Annual Conference of the IEEE Industrial Electronics Society IECON 2004, vol. 2, pp. 1172 - 1177, Korea.

[34] A. V. Timbus, R. Teodorescu, F. Blaabjerg, U. Borup, "Online grid measurement and ENS detection for PV inverter running on highly inductive grid", IEEE power electronics letters, vol. 2, no. 3, pp. 77-82, Sept. 2004.

[35] C.L. Trujillo, D. Velasco, E. Figueres, G. Garcerá, R. Ortega, "Modeling and control of a push-pull converter for photovoltaic microinverters operating in island mode," Applied Energy, vol. 88, no. 8, pp. 2824 2834, Aug. 2011.

[36] J.M. Guerrero, L. Hang, J. Uceda, "Control of Distributed Uninterruptible Power Supply Systems," IEEE Trans. on Industrial Electronics, vol.55, no.8, pp.2845-2859, Aug. 2008.

[37] R. Ortega, G. Garcerá, E. Figueres, O. Carranza, C.L. Trujillo, "Design and application of a two degrees of freedom control with a repetitive controller in a single phase inverter," Proc. of the IEEE International Symposium on Industrial Electronics (ISIE), pp.1441-1446, 27-30 June 2011.

[38] J.M. Guerrero, J. Matas, L.G. de Vicuna, M. Castilla, J. Miret, "Wireless-Control Strategy for Parallel Operation of DistributedGeneration Inverters," IEEE Trans. on Industrial Electronics, vol.53, no.5, pp.1461-1470, Oct. 2006.

[39] K. De Brabandere, B. Bolsens, J. Van den Keybus, A. Woyte, J. Driesen, R. Belmans, "A Voltage and Frequency Droop Control Method for Parallel Inverters," IEEE Trans. on Power Electronics, vol.22, no.4, pp.1107-1115, July 2007.

[40] A. Tuladhar, H. Jin, T. Unger, and K. Mauch, "Parallel operation of single phase inverter modules with no control interconnections," in Proc.IEEE-APEC'97 Conf., pp. 94-100, 1997.

[41] J.M. Guerrero, L.G. de Vicuna, J. Matas, J. Miret, M. Castilla, "A wireless controller for parallel inverters in distributed online UPS systems," Industrial Electronics Society, 2003. IECON '03. The 29th Annual Conference of the IEEE, vol.2, no., pp. 1637- 1642, Nov. 2003.

[42] T. Thacker, F. Wang, D. Boroyevich, "Islanding Control of a Distributed Generation Unit's Power Conversion System to the Electric Utility Grid", Conference on Power Electronics Specialists, PESC '05, pp. 210-216, June, 2005

[43] PSIM 7.0.5 User's Guide (2006), Powersim Inc., March 2006. 